\title{
Night cough in a population-based sample of children: characteristics, relation to symptoms and associations with measures of asthma severity
}

\author{
A.M. Brooke*, P.C. Lambert**, P.R. Burton†, C. Clarke*, D.K. Luyt*, H. Simpson*
}

Night cough in a population-based sample of children: characteristics, relation to symptoms and associations with measures of asthma severity. A.M. Brooke, P.C. Lambert, P.R. Burton, C. Clarke, D.K. Luyt, H. Simpson. C ERS Journals Ltd 1996.

ABSTRACT: Nocturnal cough in asthma is a common but poorly understood phenomenon. The aims of this study were to determine the relationship between recorded night cough, reported night cough and current wheeze in a population-based sample of children previously identified as wheezy, and to examine the relationship of nocturnal cough to current symptoms, markers of asthma severity and environmental exposure.

Children were reassessed in the early school years by measuring current symptoms, ventilatory function, bronchial reactivity, peak flow variability, respiratory symptom diaries and home monitoring of overnight cough, transcutaneous arterial oxygen saturation, room temperature and humidity. Night studies were performed on 59 asymptomatic children and 41 children with current wheeze.

Cough occurred more frequently in current wheezers compared to asymptomatic children (16 out of $41(39 \%)$ vs 11 out of $59(19 \%)$ ), and more cough episodes were recorded (median 3.5 vs 2.0). Night cough was not associated with bronchial reactivity, peak flow variability, degree of morning dip, mean overnight arterial oxygen saturation, ventilatory function, maternal smoking or treatment of asthma. However, it was associated with lower overnight air temperature.

Although night cough is more common in current wheezers, there is poor agreement between recorded and reported night cough. Objective tests of asthma severity are of little use in predicting its presence in this age group. The sleeping environment deserves further study.

Eur Respir J., 1996, 9, 65-71.
Depts of *Child Health and **Epidemiology and Public Health, University of Leicester, Clinical Sciences Building, Leicester Royal Infirmary, Leicester, UK. †Institute for Child Health Research, Princess Margaret Hospital for Children, Subiaco, Western Australia.

Correspondence: H. Simpson

Dept of Child Health

University of Leicester

Clinical Sciences Building

Leicester Royal Infirmary

P.O. Box 65

Leicester LE2 7LX

UK

Keywords: Asthma severity

childhood wheeze

environmental factors

night cough

population study

repeatability

Received: November 71994

Accepted after revision August 151995
Nocturnal symptoms are common in asthma and most asthmatics have nocturnal bouts of cough, wheeze, dyspnoea or chest tightness [1]. Studies of asthmatic adults have shown that those who are symptomatic have a poorer quality sleep [2], and that this in turn interferes with daytime activities [3]. Nocturnal cough can be a troublesome symptom in asthmatic children and can result in impairment of daytime performance. Elucidation of the mechanisms underlying nocturnal worsening of asthma remains incomplete. Putative explanations relate to circadian phenomena, such as increased bronchial responsiveness [4], increased airway lability [5], increased sensitivity to inhaled allergens [6], autonomic imbalance [7], and decreased airway calibre [8]. Circadian rhythms have been demonstrated for peak expiratory flow rate [9], bronchial responsiveness [10], and catecholamine secretion [7]. This work has shown that these cyclical phenomena reach a bathysphase (lowest point) during the night [7-10]. The timing of nocturnal cough does not tally with the bathysphase of these same measures, possibly indicating an imprecise relationship between cough and other measures of asthma severity. Clarification of the precise relationships between nocturnal cough and measures of respiratory function are further hampered by the poor reporting of nocturnal cough, particularly in children $[11,12]$. In addition, most reported studies have concerned children with severe asthma and/or asthmatics undergoing therapeutic trials to reduce night cough [13]. Finally, it has been recognized that the analysis of factors important in determining night cough may be confounded by environmental exposures, such as tobacco smoke [14], pollutants [15] and dampness [16].

We have studied night cough in a population-based cohort of children aged 4-7 yrs, who had previously been identified as having wheeze in the preschool years, with the following aims: 1) to determine the relationship between recorded night cough and recent wheeze (within the last year); 2) to compare the reported frequency of night cough with that actually recorded at night; 3) to define the nature and timing of nocturnal cough in those with and without wheeze in the preceding year; and 4) to determine whether factors, such as lung function, bronchial reactivity and environmental exposure, predict, or are associated with, nocturnal cough. 


\section{Subjects and methods}

The methods by which the original cohort of 1,422 children were recruited in the preschool period have been described in detail elsewhere [17]. At follow-up, all 222 children who had parentally reported wheeze in the preschool period were invited to attend Leicester Royal Infirmary to participate in an update symptom questionnaire and assessment of ventilatory function, bronchial responsiveness to inhaled methacholine, atopic status, peak flow variability, respiratory symptom diary and assessment of nocturnal symptoms. The timing of these studies was arranged so that children were seen when they were free from viral respiratory infections (at least 4 weeks).

Of the 222 children identified in the preschool period as having wheeze, 145 were reassessed by questionnaire to determine current symptoms and 114 (61 boys and 53 girls) attended for physiological assessment. The average age (range) of children at follow-up was 6 (4-8) yrs, and mean follow-up time (range) between the two surveys was 2.9 (1.8-4.0) yrs. Night studies were carried out on 100 children. Fifty nine of these children had been free of wheeze for at least a year prior to followup and the remaining 41 had wheezed within that year (current wheezers). In this latter group, 16 (39\%) had suffered 1-2 attacks in the past year, $21(51 \%)$ had 3-5 attacks, and $4(10 \%)$ had $\geq 6$ attacks. Twenty eight were in receipt of anti-asthma medication and 13 were not. In those being treated, 21 were receiving prophylaxis (inhaled steroids or sodium cromoglycate) and bronchodilators when required, and the remaining seven bronchodilators alone. Among the 59 subjects without current wheeze, 9 were being treated (prophylaxis and bronchodilators in four and bronchodilators alone in five).

\section{Questionnaire}

The presence of wheeze was established in the initial survey by the question "has your child ever had attacks of wheezing?" and this question was itself prefaced with a definition of wheeze as "a high pitch whistling sound coming from the chest, not the throat". At follow-up, a history of night cough was elicited by the question "Has your child at any time in the last 12 months been wakened at night by an attack of coughing when he/she does not have a cold or chest infection?" Positive responses to the latter question were then followed by an enquiry as to the regularity of the night cough, and children with more than four attacks per year were arbitrarily defined as having current night cough.

\section{Assessment of lung function and bronchial responsive- ness}

Ventilatory function was determined with a pneumoscreen II/1 (Erich Jaeger) and maximum flow rate for the middle $50 \%$ of forced expiration (MEF25-75\%) was calculated. Seventy nine children were able to use this equipment satisfactorily. Bronchial responsiveness to inhaled methacholine was assessed in 76 children using the tidal breathing method of Cockcroft, and response to methacholine was indirectly measured using changes in transcutaneous oxygen tension $\left(P \mathrm{tc}, \mathrm{O}_{2}\right)$ [18]. The concentration of methacholine required to produce a $20 \%$ decrease in $\mathrm{Ptc}_{\mathrm{tc}} \mathrm{O}_{2}$ from baseline (presaline) was calculated using linear interpolation of points on the logged dose-response curve which bracketed the predicted $20 \%$ decrease $\left(\mathrm{PC}_{20} \mathrm{Ptc}_{\mathrm{tc}} \mathrm{O}_{2}\right)$. All subjects in this report responded before the final dose (maximum dose $32 \mathrm{mg} \cdot \mathrm{mL}^{-1}$ ). Baseline peak expiratory flow rate (PEFR) was measured in 80 children using a mini-Wright peak flow meter (Clement-Clarke). MEF25-75\% and PEFR were expressed as percentage predicted for height using the equations of Zapletal et al. [19] and WiLle and Svensson [20].

\section{Peak flow and respiratory symptom diary}

A 2 week diary was completed satisfactorily by 74 children by recording the best of three PEFRs three times a day at exactly 8 a.m., 4 p.m. and 8 p.m.. At the same time, a 5-point diary was completed regarding symptoms and treatment, which included specific separate questions concerning cough during the day and cough waking the child at night. In 47 subjects it was possible to obtain a measure of morning dip by subtracting the PEFR (as percentage predicted) recorded at 8 a.m. following the night study from the recording taken at 8 p.m. on the night of study.

\section{Overnight study}

Cough was recorded overnight using a noise-activated timed tape system placed in the child's bedroom. At the same time, the transcutaneous arterial oxygen saturation was monitored over the course of the night using a Biox pulse oximeter and finger probe (Ohmeda, B.O.C). The saturation was recorded and stored on data loggers (Grant Instruments, Cambridge, UK) at 1 min intervals. In addition, room temperature and the humidity of room air was also recorded and stored at $1 \mathrm{~min}$ intervals throughout the study.

The following morning, all data were retrieved and downloaded for analysis. The cough tape was listened to and extraneous noises (for example throat clearing and snoring) were excluded. The number of cough episodes per hour of the night and the total number of coughs heard in that hour were recorded. For the purposes of our study, night cough was defined as the presence of at least one episode of multiple coughing. This excluded children with repeated episodes comprising a single cough. The saturation record was analysed using purpose-designed software, which ignored saturation readings recorded when a low pulse rate was present in order to exclude erroneously low readings resulting from poor probe contact. However, few data were lost from the studies in this way. In order to assess the repeatability of the night study, 30 children were asked to repeat the entire protocol, and this included an repeat overnight study. The mean time (range) between initial assessment and assessment of repeatability was 9 (1-20) months. 
Table 1. - Relationship between measures of night cough in previously wheezy children and children with current wheeze

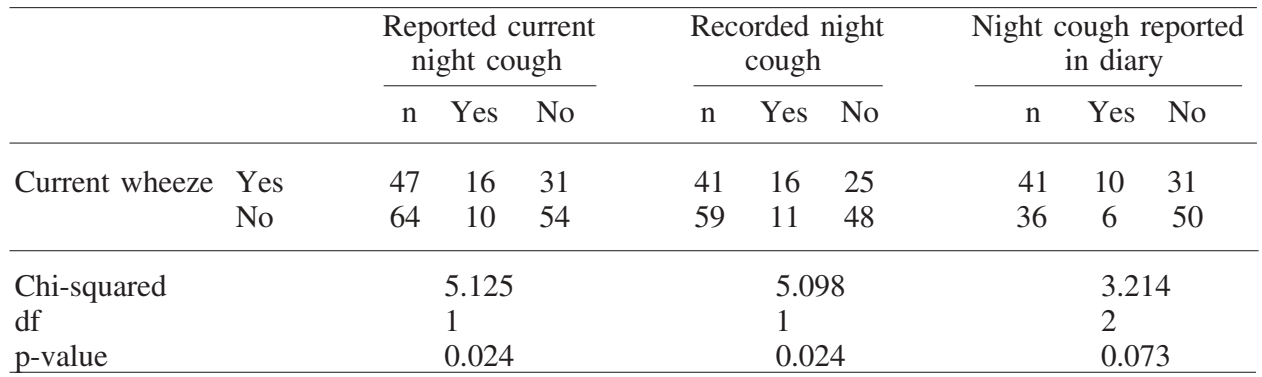

\section{Statistical methods}

Data were analysed using Statistical Analysis Software (SAS) [21] and S-plus [22]. Categorical data were presented using contingency tables and formal statistical inference was based upon the Chi-squared test for homogeneity (without continuity correction) [23]. The repeatability of binary outcomes was assessed using percentage agreement and more formally by Cohen's kappa (к) statistic. The Wilcoxon rank sum test was used to compare total number of coughs and total number of cough episodes recorded overnight between groups of children, as these data were nonparametrically distributed. A p-value of less than 0.05 was accepted as statistically significant.

\section{Results}

\section{Night cough and its relationship with current wheeze}

At least one episode of multiple nocturnal cough was recorded in 11 out of 59 children from the current asymptomatic group, and in 16 out of 41 of the children with current wheeze $\left(\chi^{2}=5.10 ; p=0.024\right)$. In the asymptomatic children, the median (range) number of cough episodes heard overnight was 2.0 (1-4), which was lower that heard in the wheezy group where the equivalent figures were 3.5 (1-83) (Wilcoxon scores (rank sums), $\mathrm{p}=0.033$ ). The median (range) for the total number of coughs heard overnight in these two groups was 5 (2-24) and 11 (2-94) for the asymptomatic and wheezy groups, respectively (Wilcoxon scores (rank sums), $\mathrm{p}=0.125$ ).

Table 1 shows the rate of night cough detected by questionnaire or recorded overnight in previously wheezy children, depending on current wheeze status. A higher proportion of children with current wheeze reported night cough within the previous year, and night cough was actually recorded in a higher proportion of children with current wheeze. There was a borderline difference in the proportions reporting night cough in the symptom diary between persistent wheezers and in those whose wheeze had ceased.

Repeat overnight recordings were completed on 27 children. In this group, four were heard to cough on both nights, 16 did not cough on either night, and seven coughed on one of the two nights. This translates to a percentage agreement of $74 \%$ and a Cohen's $\kappa$ of 0.36 .
Agreement between different methods of assessing night cough

The relationship between reported and recorded night cough was relatively poor (table 2) with low values of Cohen's kappa for agreement between the different methods of reporting the presence of night cough. For example, night cough was reported in the symptom diary for 15 subjects, but was only recorded in six. Similarly, night cough was not reported in the symptom diary for 73 subjects, but was recorded in 18 .

\section{Timing of night cough}

Figure 1 illustrates the chronology of nocturnal cough by comparing timing of multiple cough episodes between children who were wheezy or wheeze-free at follow-up. It can be seen that children who were free of wheeze coughed little overnight, but that most of this coughing occurred in the morning between 5 and 7 a.m. A similar proportion of children with wheeze at follow-up coughed at night but these episodes occurred throughout the night, with most coughing occurring early in the night between 8 and 10 p.m.

\section{Night cough and asthma severity}

The relationship between the asthma-related outcomes measured and the presence of recorded night cough, depending on whether wheeze was still present at follow-up can be seen in table 3 . It can be seen that children with persistent wheeze have poorer ventilatory function, decreased mean overnight saturation, increased bronchial responsiveness, increased peak flow variability and increased degree of morning dip when compared to children who are wheeze-free. However, the presence

Table 2. - Relationship between recorded night cough and reported night cough

\begin{tabular}{llrrrcc}
\hline & & \multicolumn{3}{c}{$\begin{array}{c}\text { Recorded } \\
\text { night cough }\end{array}$} & Agreement & $\begin{array}{c}\text { Cohen's } \\
\text { Kappa }\end{array}$ \\
\cline { 2 - 5 } & & n & Yes & No & $\%$ & \\
\hline $\begin{array}{l}\text { Current night } \\
\text { cough }\end{array}$ & Yes & 22 & 8 & 14 & & \\
& No & 77 & 20 & 57 & 66 & 0.09 \\
$\begin{array}{l}\text { Night cough } \\
\text { reported in }\end{array}$ & Yes & 15 & 6 & 9 & 69 & 0.12 \\
$\begin{array}{l}\text { symptom diary } \\
\text { Sy }\end{array}$ & 73 & 18 & 55 & & \\
\hline
\end{tabular}



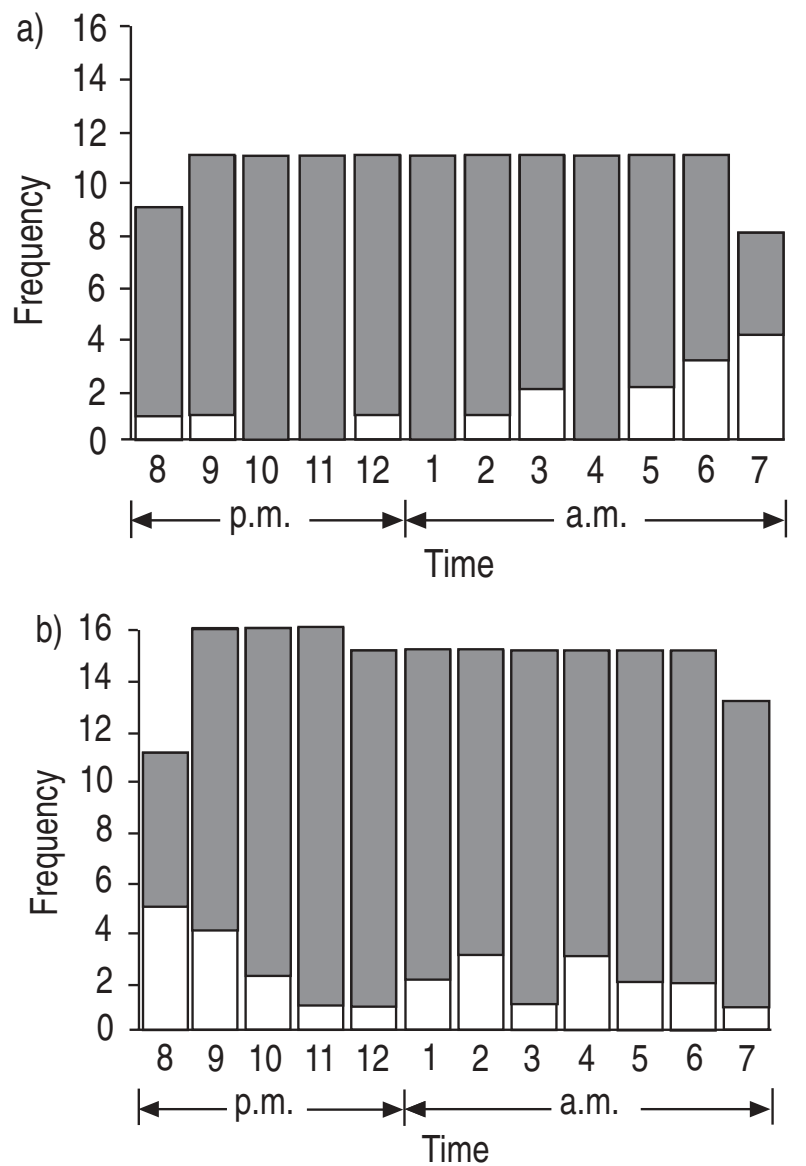

Fig. 1. - Timing of cough episodes overnight in: a) children who were wheeze-free at follow-up; and b) children who were wheezy at follow-up. $\square$ : number without cough; $\square$ : number with cough. of recorded night cough was not associated with large changes in any of these putative markers of asthma severity for either current or past wheezers.

\section{Effect of treatment on night cough}

In the "treated" subgroup of current wheezers, night cough was heard in 10 out of 28 compared to 6 out of 13 in the "untreated" group $\left(\chi^{2}{ }_{1}=0.407 ; \mathrm{p}=0.52\right)$. Corresponding proportions for the children without current wheeze were 3 out of 9 and 8 out of $50\left(\chi^{2}=1.51 ; \mathrm{p}=0.22\right)$. The small numbers preclude separate analysis for treated and untreated children. Results are presented for the total number of children studied, on the grounds that recorded night cough was comparable in both treated and untreated subgroups of children.

\section{Night cough and the domestic environment}

Table 4 details the temperature and humidity measurements recorded during the night studies and examines the relationship with night cough and environment, depending on the presence or absence of current wheeze. Due to problems with data retrieval following the night studies, only 32 overnight temperature records were available for analysis. However, it can be seen that in children with persistent wheeze, the presence of night cough was associated with decreased temperature, whilst there was a borderline association with increased humidity.

Out of the 41 subjects with current wheeze, 15 children had mothers who smoked and 26 had not. In the former group night cough was heard in 6 out of 15

Table 3. - Relationship between recorded night cough and other asthma-related outcomes

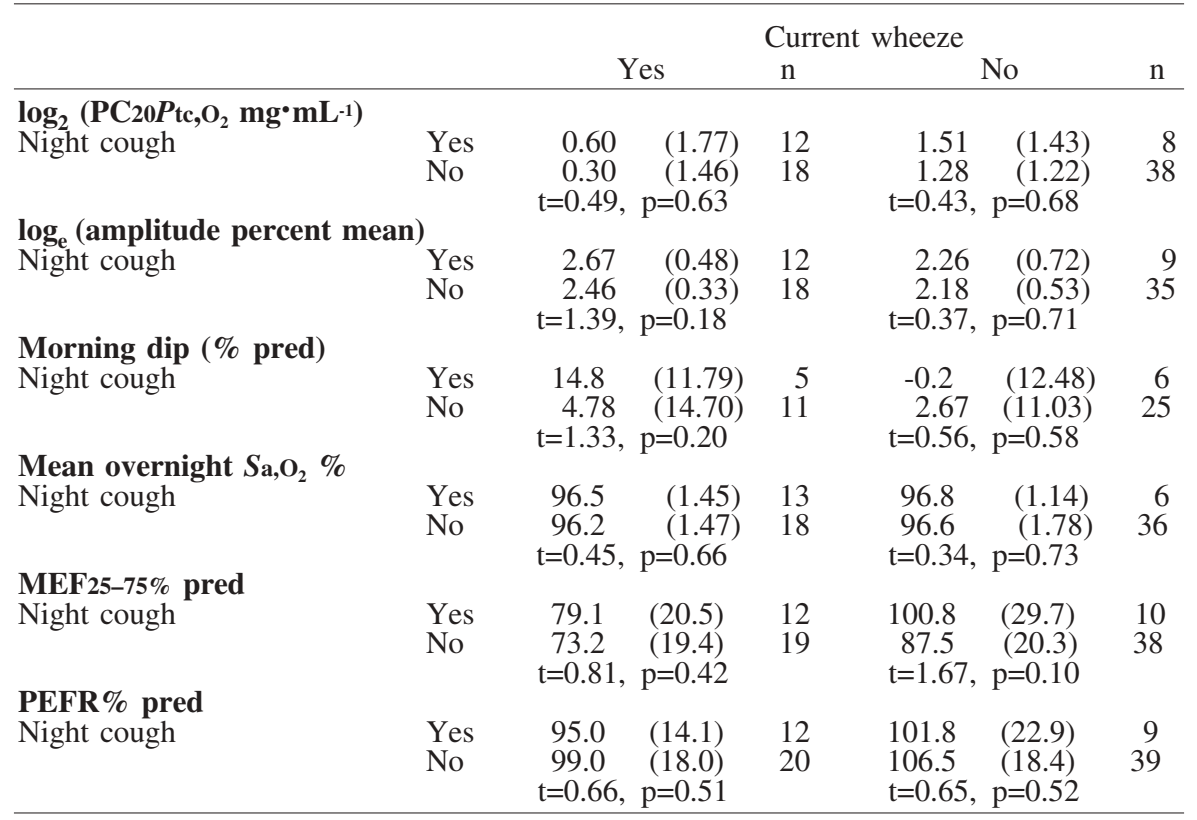

Values are presented as mean, and SD in parenthesis. PC20: concentration of methacholine provoking a $20 \%$ decrease in forced expiratory volume in one second; $P \mathrm{tc}, \mathrm{O}_{2}$ : transcutaneous oxygen pressure; $\mathrm{Sa}_{\mathrm{a}} \mathrm{O}_{2}$ : arterial oxygen saturation; $\mathrm{MEF} 25-75 \%$ : maximum mid-expiratory flow; PEFR: peak expiratory flow rate; $\%$ pred: percentage of predicted. 
Table 4. - Relationship between recorded night cough and the overnight bedroom environment

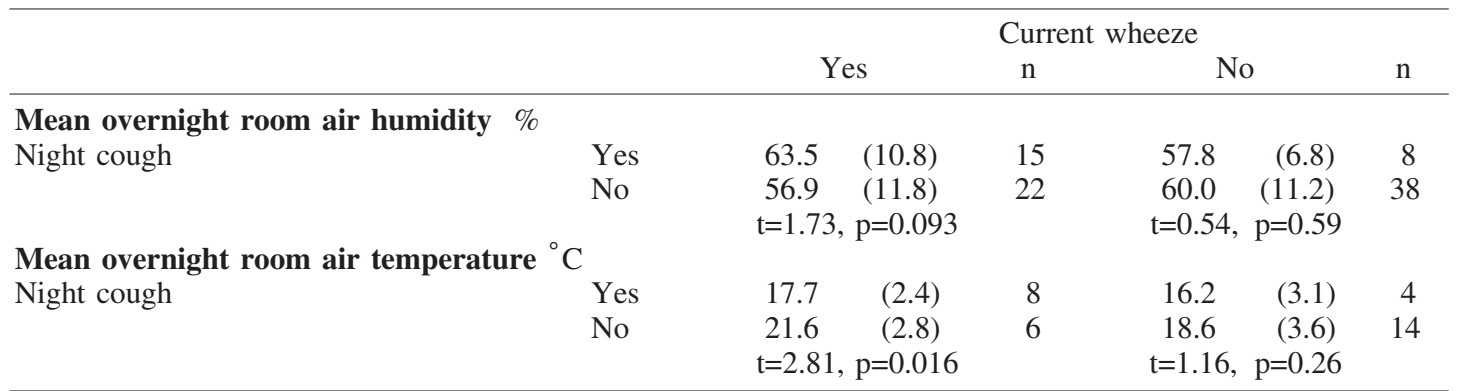

Values are presented as mean, and SD in parenthesis.

compared to 10 out of 26 for children with nonsmoking mothers. These proportions were similar $\left(\chi^{2}{ }_{1}=0.009\right.$; $\mathrm{p}=0.92)$. Out of the 59 subjects without current wheeze, 10 children had mothers who smoked and 49 had not. In the first group, night cough was heard in 1 out of 10 compared to 10 out of 49 for children with nonsmoking mothers. These proportions were also similar $\left(\chi^{2}{ }_{1}=0.593\right.$; $\mathrm{p}=0.44$ ).

\section{Discussion}

This study has shown that among a population-based sample of children identified as wheezy during the preschool years and reassessed in the early school years, night cough is significantly greater in current wheezers than in children who were wheeze-free in the preceding year. There was, however, poor agreement between recorded and reported night cough. Night cough was unrelated to putative indices of asthma severity - ventilatory function status, bronchial reactivity, peak flow variability and mean overnight oxygen saturation - but was associated with lower overnight ambient room temperature $(\mathrm{p}=0.016)$.

\section{Night cough and current wheeze status}

The significant relationship found between night cough (reported or measured) and current wheeze status in the children studied is hardly surprising, despite the limitations of measures of night cough. The designation of current night cough was based upon questionnaire enquiry. It depended on parental recall and referred only to night cough that resulted in awakening. Similarly, diary card assessments of night cough; required the child to be awakened by cough even if reporting was accurate, the frequency of night cough was almost certainly under estimated. Objective monitoring of night cough over a period of weeks or even days is limited by the lack of commercially available monitors that are inexpensive, portable, safe, accurate and suitable for recording night cough in large numbers of children simultaneously over a significant time period. In the study, the overnight recording made on a random night during the 2 weeks which followed the clinical assessment merely registered a "snapshot" of overnight coughing, which should not be regarded as representative of the overall clinical picture. Not surprisingly, the repeatability was relatively poor and due, in part, to the long interval between assessments.

In this study, at least one episode of multiple coughing was required to be heard before children were regarded as having recorded night cough. Other studies have considered night cough to be present on the basis of a single cough recorded during an overnight period. We felt that this criterion would have been too sensitive and risked obscuring important differences between children with or without significant nocturnal cough. In the event, the proportion of children recording single episodes of cough was similar to the proportion recording episodes of multiple cough. Twelve out of 59 (20\%) currently asymptomatic recorded at least one single cough overnight compared to 11 out of $59(19 \%)$ recording at least one episode of multiple coughing. The equivalent figures for the currently wheezy group were 18 out of $41(44 \%)$ and 16 out of $41(39 \%)$, respectively. Thus, about $40 \%$ of currently wheezy children from our sample were heard to cough overnight, whilst $36 \%$ were reported to cough at night regularly. The smaller proportion with diary reported night cough is consistent with the underreporting noted in other studies [11]. The poor agreement between reported and recorded night cough (table 2) reflects not only the different methods employed but the varying time spans over which coughing was assessed.

The timing of recorded night cough episodes is of interest. Children who were wheeze- free at follow-up tended to cough in the mornings, whereas those with current wheeze coughed throughout the night, particularly in the early part of the night. This is similar to the observation of THOMsON et al. [24] who found that the timing of night cough in asthmatic children varied during the night and was out of phase with the nadir in peak flow [9]. There is no published information on the precise timing of cough during the night in various respiratory disorders in which cough, is prominent. Variations in the timing of night cough might reflect differing mechanisms that are dependent on the sites and/or pathology of any underlying respiratory disorder. Thus, the timing of cough associated with upper respiratory tract disorders, for example enlarged tonsils and adenoids, may differ from that seen with certain lower respiratory illnesses; similarly, lower respiratory conditions characterized by wheezing and cough, e.g. asthma and recurrent aspiration, may have different patterns of cough. In the present 
study, care was taken to avoid the potentially confounding effects of upper respiratory viral illnesses, and none of the children were thought to have definable underlying lung disease, such as cystic fibrosis. We cannot explain variations in timing of night cough which may also have resulted from aspects of the sleeping environment not investigated here.

\section{Night cough and putative measures of asthma severity}

Analysis of the putative measures of asthma-severity indicated that although current wheezers were on the whole more severe (increased bronchial reactivity, peak flow variability and decreased ventilatory function), there was little association between these measures and the presence of recorded night cough for either current or past wheezers. A detailed investigation of the relationship between current and past wheeze in this group of children is reported elsewhere [25]. In the case of bronchial reactivity, the lowest value for this index was seen in the children in whom no cough was heard, which was the opposite of what may have been expected. This runs counter to the hypothesis that excessive airway reactivity is an important or even sole determinant of night cough. Similarly, differences in mid-expiratory flow and peak expiratory flow were not associated with the presence of night cough, indicating that night cough is not strongly related to these aspects of ventilatory function. Although an increased variability and increased morning dip was found to be present in currently wheezy children with recorded cough, the change was not statistically significant. This is in apparent contrast with literature, where excessive morning dip and peak flow variability have been used to predict nocturnal worsening of asthma [5]. Children with recorded night cough had similar mean levels of arterial oxygen saturation to those in whom coughing did not occur. This differs from the reported findings in children recovering from acute attacks of asthma [26], in whom night cough was much more prominent. The study was of a community-based sample of children who were well or had well-controlled asthma. This may explain why we were unable to demonstrate a relationship between the presence of recorded night cough and these indices of asthma severity. Our data also show that the receipt of anti-asthma medication made little impact on the proportion of children with recorded night cough, although it should be borne in mind that the sample size is relatively small.

\section{Environmental influences}

The data on overnight temperature showed that lower average temperatures were associated with overnight cough, and significantly so for those children with current wheeze despite the fact that, due to problems with data handling, only 32 observations were available for analysis. This contrasts with previous data $[27,16]$. A borderline association of increased humidity was also found for current wheezy children with nocturnal cough. Although the presence of patches of mould or damp are associated with nocturnal worsening of asthma, data on the effect of humidity have previously shown no specific association [16]. No effect of maternal smoking was shown, which is contrary to many other large scale epidemiological studies, although these looked at reported night cough rather than recorded night cough [14].

When interpreting these data it is important to appreciate the cross-sectional nature of the initial cohort and the differential follow-up time. It could be argued that young children are more likely to have night cough in response to viral infections than their older counterparts, and hence the age structure of the cohort may obscure the relationships investigated above. Children were investigated only during periods free from viral respiratory infections (at least 4 weeks from last infection) and in this way we hoped to circumvent this problem. It would also be possible (given the study design) that children could have developed viral respiratory infections in the time between the initial visit to the hospital and the home visit. In the event, only one child developed such an infection and was excluded from the analysis. Since the factors investigated are likely to be correlated (e.g. a higher proportion of current wheezers were on antiasthma treatment), unconditional logistic regression was performed using recorded night cough $(0=$ no, $1=$ yes $)$ as the binary outcome. This also allowed the appropriate investigation of age and follow-up time. In the event, this did not alter any of the inferences already discussed, as no factors other than room temperature were found to predict the presence of recorded night cough.

In conclusion, this study has examined recorded night cough and its relationship to current symptoms in a community-based sample of children known to have wheezed in the preschool period. It has demonstrated that a significantly greater proportion of children with current wheeze cough at night compared to their asymptomatic counterparts. There is poor agreement between recorded and reported night cough, and the presence of night cough was not associated with any other aspect of lung function or measure of asthma severity. Recorded night cough was associated with colder and more humid environments, but no effect of maternal cigarette smoking was seen. Prescribed anti-asthma medication had little effect on the occurrence of recorded night cough.

In summary, this common accompaniment to current wheeze is underreported and hard to predict in young children from observing other measures of lung function. Treatment of wheeze seems to have little effect on recorded cough, and further studies are needed to establish whether low environmental temperature and high humidity is truly associated with recorded night cough. Ideally, any future study should also incorporate an objective assessment of upper respiratory tract symptoms and signs.

Acknowledgements: The authors thank the National Asthma Campaign for their financial support and all the parents and children who participated in the study.

\section{References}

1. Turner Warwick M. Epidemiology of nocturnal asthma. Am J Med 1988; 85: 6-8. 
2. Montpalisir J,Walsh J, Malo JL. Nocturnal asthma: features of attacks, sleep and breathing patterns. Am Rev Respir Dis 1982; 125: 18-22.

3. Fitzpatrick MF, Engleman H, Whyte KF, Deary IJ, Chapiro CM, Douglas NJ. Morbidity in nocturnal asthma: sleep quality and daytime cognitive performance. Thorax 1991; 46: 569-573.

4. Wempe JB, Tammeling EP, Postma DS, Auffarth B, Teengs JP, Koeter GH. Effects of budesonide and bambuterol on circadian variation of airway responsiveness and nocturnal symptoms of asthma. J Allergy Clin Immunol 1992; 90: 349-357.

5. Bellia V, Visconti A, Insalaco G, Cuttitta G, Ferrara G, Bonsignore G. Validation of morning dip of peak expiratory flow as an indicator of the severity of nocturnal asthma. Chest 1988; 94: 108-110.

6. Platts-Mills TAE, Mitchell EB, Nock P, Tuvey ER, Moszoro H, Wilkins SR. Reduction of bronchial hyperreactivity during prolonged allergen avoidance. Lancet 1982; ii: 675-677.

7. Bates ME, Clayton M, Calhoun W, et al. Relationship of plasma epinephrine and circulating eosinophils to nocturnal asthma. Am J Respir Criti Care Med 1994; 149: 667-672.

8. Gaultier C, Reinberg A, Girard F. Circadian rhythms in lung resistance and dynamic lung compliance of healthy children. Respir Physiol 1977; 31: 169-182.

9. Johnson IDA, Anderson HR, Patel S. Variability of peak flow in wheezy children. Thorax 1984; 39: 583-587.

10. Martin RJ, Cicutto LC, Ballard RD. Diurnal variation of airway reactivity in normals and asthmatics (Abstract). Am Rev Respir Dis 1987; 135(4): A230.

11. Archer LNJ, Simpson H. Night cough counts and diary card scores in asthma. Arch Dis Child 1985; 60: 473-474.

12. Falconer A, Oldman C, Helms, P. Poor agreement between reported and recorded nocturnal cough in asthma. Pediatr Pulmonol 1993; 15: 209-211.

13. Hoskyns EW, Thomson A, Decker E, Hutchins A, Simpson $\mathrm{H}$. Effect of controlled release salbutamol on nocturnal cough in asthma. Arch Dis Child 1991; 66: 1209-1212.

14. Somerville SM, Rona RJ, Chinn S. Passive smoking and respiratory conditions in primary school children. $J$ Epidemiol Commun Health 1988; 42: 105-110.

15. Ostro BD, Lipsett MJ, Mann JK, Wiener MB, Selner J.
Indoor air pollution and asthma: results from a panel study. Am J Respir Crit Care Med 1994; 149: 1400-1406.

16. Strachan DP, Sanders CH. Damp housing and childhood asthma; respiratory effects of indoor air temperature and relative humidity. J Epidemiol Commun Health 1989; 43: 7-14.

17. Luyt DK, Burton PR Simpson H. Epidemiological study of wheeze, doctor diagnosed asthma and cough in preschool children in Leicestershire. Br Med J 1993; 306: 1386-1390.

18. Wilson NM, Phagoo SB, Silverman M. Use of transcutaneous oxygen tension, arterial oxygen saturation, and respiratory resistance to assess the response to inhaled methacholine in asthmatic children and normal adults. Thorax 1991; 46: 433-437.

19. Zapletal A, Paul T, Samanek M. Die bedeutung heutiger methoden da lungenfunktionsdiagnostik zur feststellung einer obsruktion der atemwege bei kindern und jugendlichen. Z Erkr Atmorg 1977; 149: 343-371.

20. Wille S, Svensson K. Peak flow in children aged 4-16 years: normal values for vitalograph peak flow monitor, wright and mini-Wright peak flow meters. Acta Paediatri Scand 1989; 78: 544-548.

21. Statistical Analysis Software. Cary, North Carolina. SAS Institute Inc., 1985.

22. Becker RA, Chambers JM, Wilks AR. The new S language: a programming environment for data analysis and graphics. Pacific Grove, California, Wadsworth and Brooks/Cole Books and Software, 1988.

23. Armitage P, Berry G. In: statistical Methods in Medical Research. 2nd edi. Oxford. Blackwell Scientific, 1987.

24. Thomson AH, Pratt C, Simpson H. Nocturnal cough in asthma. Arch Dis Child 1987; 62: 1001-1004.

25. Brooke AM, Lambert PC, Burton PR, Clarke C, Luyt DK, Simpson H. The natural history of respiratory symptoms in preschool children. Am J Respir Crit Care Med 1995; (in press).

26. Hoskyns EW, Heaton DM, Beardsmore CS, Simpson H. Asthma severity at night during recovery from an acute asthmatic attack. Arch Dis Child 1991; 66: 1204-1208.

27. Melia RJW, de Ve Florey C, Morris RW, Goldstein BD, Clark D, John HH. Childhood respiratory illness and the home environment. II. Association beween respiratory illness and nitrogen dioxide, temperature and relative humidity. Int J Epidemiol 1982; 11: 164-169. 